\title{
EI NIÑO ENTRE CUATRO Y CINCO AÑOS: CARACTERÍSTICAS DE SU DESARROLLO SOCIOEMOCIONAL, PSICOMOTRIZ Y COGNITIVO-LINGÜÍSTICO
}

\author{
Jeanneth Cerdas Núñez \\ Ana Polanco Hernández \\ Patricia Rojas Núñez
}

Recibido 18-III-2002

Resumen: Este artículo corresponde a un perfil teórico del infante costarricense cuya edad oscila entre cuatro y cinco años. Contempla algunas de las características del desarrollo socioemocional, psicomotriz y cognitivo-lingüístico de esta población.

Su propósito es enriquecer el Programa de Estudio del Ciclo Materno Infantil propuesto por el Ministerio de Educación Pública, brindando al docente que atiende infantes del Grupo Interactivo II, información básica que le permita identificar la etapa del desarrollo en que se encuentran estos niños, de manera que les pueda ofrecer un proceso educativo acorde a sus necesidades e intereses.

La caracterización que se expone se definió con el aporte de diversos especialistas en el campo de la salud y la educación. Razón por la cual los datos presentados no estuvieron sujetos a estandarización alguna, sino que se describen con base en el conocimiento y la experiencia de cada uno de los profesionales citados. Se complementa la información con la teoría que aporta la bibliografía existente con respecto al desarrollo del niño.

Para efectos de presentación, el perfil que se describe se ha dividido en cuatro apartados: características generales del desarrollo físico, área socioemocional, área psicomotriz y área cognitivo-lingüística.
Aceptado 09-IV-2002

\section{Introducción}

El 29 de febrero del año 2000, el Consejo de Educación Superior de nuestro país aprobó el primer Programa de Estudio para el Ciclo Materno Infantil, que comprende la atención de los niños y niñas desde su nacimiento hasta su incorporación al Ciclo de Transición.

Este programa de estudio se comenzó a operacionalizar a partir de este mismo año con un plan piloto que involucró 1123 niños y niñas con edades comprendidas entre los cuatro años, seis meses y cinco años, seis meses. Se denomina dicho intervalo de edad: Grupo Interactivo II.

Con el fin de enriquecer esta propuesta del Ministerio de Educación Pública, se consideró oportuno, en el marco del Programa de Maestría en Planificación Curricular de la Universidad de Costa Rica, establecer un perfil teórico del infante costarricense cuya edad oscila entre cuatro y cinco años, para determinar sus principales características de desarrollo socioemocional, psicomotriz y cognitivo-lingüístico.

Fue así como surgió el presente trabajo cuyo objetivo fundamental es brindarle al docente de educación inicial que atiende este grupo de edad, información básica que le permita identificar la etapa del desarrollo en que se encuentran estos 
niños, para que les pueda ofrecer un proceso educativo acorde a sus necesidades e intereses.

Se definió el intervalo de edad entre cuatro y cinco años porque es el que usualmente manejan los especialistas para efectos de caracterización, el mismo incluye un margen en el desarrollo del niño de seis meses antes y seis meses después de la edad establecida. En términos prácticos, esto significa que dicho intervalo involucra infantes desde tres años, seis meses hasta cinco años, seis meses, rango dentro del cual se ubican los niños del Grupo Interactivo II.

La caracterización que se expone se realizó con el aporte de diversos especialistas en el campo de la salud y la educación (neurodesarrollista, pediatra, psicóloga, especialista en educación preescolar, especialista en educación física y lingüista).

La información se recopiló por medio de una entrevista no estructurada, en la que se abordaron las características generales del desarrollo del niño desde la óptica de cada uno de los especialistas. Posteriormente se organizó la información obtenida y se complementó con la teoría que aporta la bibliografía existente con respecto al desarrollo del niño.

Dada esta dinámica de trabajo, es importante señalar que los datos que se presentan no estuvieron sujetos a estandarización alguna, sino que se describen con base en el conocimiento y la experiencia de cada uno de los profesionales citados y la revisión bibliográfica realizada.

Para efectos de presentación, el perfil que se describe se ha dividido en cuatro apartados: características generales del desarrollo físico, área socioemocional, área psicomotriz y área cognitivo-lingüística. No obstante, es importante señalar que se reconoce al niño como un ser integrado, lo cual implica que su desarrollo también se da de manera integral.

\section{Características generales del desarrollo físico}

Según el neurodesarrollista Luis López, en términos del desarrollo humano, los niños entre los cuatro y cinco años se encuentran en la culminación de un período muy importante de desarrollo, pues han logrado una serie de estructuras a nivel neural, muy bien conformadas. A la edad de cuatro años su cerebro es extremadamente plástico (plasticidad cerebral), en términos de desarrollo de las funciones cerebrales, esto permite que si antes de esta edad sucede una situación anormal, como por ejemplo, un daño cerebral, el niño pueda recuperarse en un alto porcentaje. Ya a los cinco años esta plasticidad cerebral disminuye debido a que se han estabilizado los circuitos neuronales que se encargan del cerebro, por ejemplo, los correspondientes al lenguaje ya están establecidos (Comunicación personal, abril 19, 2000).

El pediatra Jorge Ureña manifiesta que los niños a esta edad ya tienen bien desarrollada la visión y la audición, por lo que se recomienda realizar un examen de agudeza visual y una audiometría anualmente. También la dentición está casi completa, ya pueden comer prácticamente de todo. El sistema digestivo y enzimático está lo suficientemente maduro para poder digerir todo tipo de alimento. El peso promedio de estos niños oscila entre 16 y 18 kilos, y la talla entre $105 \mathrm{~cm}$. y $107 \mathrm{~cm}$. A esta edad, ya deben controlar esfínteres, si no lo hacen se recomienda tomar medidas específicas, incluso acudir a algún médico para hacer una valoración que indique la posible causa del problema (Comunicación personal, abril 17, 2000).

La psicóloga Ana Teresa León (1998) señala que la mayoría de los sistemas, en especial el óseo, el muscular y el nervioso ya están funcionando prácticamente de forma madura. El tamaño de los huesos aumenta, se endurecen cada vez más y se acelera el desarrollo de los músculos grandes, 
por lo que estos niños pueden demostrar más habilidad en el campo motor. Al respecto Mussen (1978) señala que durante este período continúa aumentando su peso y estatura, y que por lo general los niños tienden a ser más pesados y las niñas a tener más tejido graso.

El doctor Ureña enfatiza que es importante observar que el infante físicamente luzca bien, de no ser así ésto puede ser un indicador para el adulto de alguna alteración crónica o maligna que se manifiesta en el niño, por ejemplo, si se ve pálido podría ser una señal de alguna enfermedad, dado que a esta edad la hemoglobina ya debe tener un nivel normal, también si se muestra cansado (Comunicación personal, abril 17, 2000).

Este especialista comenta que a esta edad es frecuente que las niñas presenten problemas de infecciones urinarias, situación que se da porque se entretienen mucho jugando, o por su condición fisiológica de la cercanía de la vejiga con el recto; principalmente si al ir al baño no se limpian adecuadamente, es decir, no se asean de adelante hacia atrás sino que lo hacen a la inversa, y esto les puede causar las infecciones.

Por otro lado manifiesta que cuando los niños hacen su primer ingreso a un centro infantil tienden a contaminarse y a contagiarse de infecciones, porque no están acostumbrados a estar en contacto con niños que presentan una flora bacteriana diferente o que podrían portar algún tipo de virus. Señala el especialista, que de esta manera se pueden iniciar las epidemias, y recomienda dejar que los niños las superen naturalmente, es decir, sin suministrar medicamento alguno, esto con el propósito de permitirles terminar de desarrollar la memoria inmunológica.

El doctor Ureña también señala que en esta edad los niños son más propensos a contagiarse de enfermedades como la varicela, el sarampión, la rubéola, la hepatitis o lo que se conoce como enfermedades propias de la infancia. Para cada una de ellas existe vacuna, por lo que recomienda que los padres estén pendientes de ponerlas a sus hijos en el momento oportuno (Comunicación personal, abril 17, 2000).

Según este pediatra, antes de que el niño cumpla los cuatro años suele ser muy controlado por sus padres, principalmente en lo que respecta a su salud, porque en los primeros años se enferma con mayor frecuencia. Por ejemplo, en el primer año de vida se enferma de 5 a 7 veces. Ya a los cuatro años el infante va al médico una vez al año para control y para que se le realicen exámenes de laboratorio, a esta edad el niño prácticamente no se enferma, sus padres consultan al doctor sólo por algo especial, básicamente por infecciones en las vías respiratorias, por un accidente como trauma de cráneo, o fracturas, o bien por hiporexia psicológica (falta de apetito), lo que es normal a esta edad.

$\mathrm{Al}$ respecto el doctor explica que el niño en esta etapa casi no come, esto representa un estancamiento fisiológico normal para su edad; el patrón de alimentación a esta edad es que el niño un día come muy bien y otro muy mal, o come muy bien tres días y no lo hace por otros cuatro. Además, su interés por conocer e investigar, así como el juego, suelen ser mucho más importante que la comida.

En relación con esta situación, la especialista en Educación Preescolar, Licenciada Ana Isabel Fonseca, señala que los gustos alimenticios de los niños de acuerdo con lo que ella ha observado en aulas preescolares, van dirigidos hacia el consumo de productos que contengan azúcar y mucho líquido (Conversación personal, marzo 15, 2000).

El doctor Ureña señala que a esta edad no es recomendable darle exceso de leche al niño para tratar de sustituir algún alimento que no ingiera, porque en alguna forma se neutralizan los micro nutrientes, por ejemplo la absorción del hierro. Si el niño come muy poquito pero se toma un 
gran biberón o vaso de leche, está neutralizando todo el hierro y otros nutrientes que no serán aprovechados, porque los líquidos aceleran el vaciamiento gástrico y el proceso de digestión, al pasar rápidamente por el estómago e impedir el contacto con las mucosas para ser absorbidos, por eso después se dan las carencias de estos nutrientes (Comunicación personal, abril 17, 2000).

El doctor agrega que no es prudente darles vitaminas y preparados a los niños para abrir el apetito, porque lo que hacen es acelerar el cierre de los núcleos de osificación, lo que provoca problemas en su crecimiento. Únicamente se recomienda utilizar este tipo de complementos cuando el niño está recuperándose de una infección, o cuando tiene deficiencias en el desarrollo.

Finalmente este especialista enfatiza la importancia de fomentar a esta edad el hábito de una alimentación sana para evitar en la vida adulta enfermedades crónicas como por ejemplo las cardiovasculares, diabetes, u obesidad. En este sentido recomienda a las docentes de este nivel fortalecer en los niños el hábito de comer frutas y verduras, así como la práctica de realizar ejercicio diario; señalando también la necesidad de trabajar con los padres de familia para crear conciencia y empezar a cambiar estilos de vida.

\section{Área socioemocional}

Esta área involucra un proceso mediante el cual el niño adquiere conductas, y construye creencias, normas, actitudes y valores; propios del medio familiar y cultural en el que se desenvuelve; con el propósito de establecer relaciones armoniosas consigo mismo, con los demás y con el medio que le rodea.

Según la especialista en educación preescolar, Licenciada Ana Isabel Fonseca, el período de edad entre los cuatro y cinco años de vida del niño es como un puente, dado que constituye la suma de logros del bebé y el potencial increíble del niño más grande. De esta manera, el niño se siente poderoso, está haciendo una identificación de sí mismo, y por esta razón es capaz de decirle a la maestra, no quiero, no me da la gana, como al instante decir niñita perdóname, te amo (Comunicación personal, marzo 15, 2000).

$\mathrm{Al}$ respecto, el pediatra Jorge Ureña señala que éste es un niño que quiere tocar y probar lo que está a su alrededor, por lo que en ocasiones llega a tener ciertos conflictos con sus padres, quienes deben saber manejarlo, porque si no acabarían diciéndole no a todo lo que el niño realiza desde que se levanta hasta que se acuesta, por ejemplo: no haga, no toque, no vea, cuidado se va en el hueco, cuidado con la bicicleta; por esta razón recomienda que los padres busquen un balance para manejar los límites sin coartar la curiosidad del niño (Comunicación personal, abril 17, 2000).

El neurodesarrollista Luis López, agrega que el niño de cuatro a cinco años prueba diariamente, es el chiquillo típico de no haga eso. A esta edad puede ser un niño berrinchoso oposicional, que saca de casillas a todo mundo, el que dice "yo no quiero", "yo no como", el que le punza los ojos a los hermanos, etc; es un niño difícil, capaz de imponerse. Según este especialista a esta edad el niño aún no tiene reglas establecidas, apenas las está construyendo en su relación con la gente (Comunicación personal, abril 19, 2000).

Fonseca, explica que este niño es muy dado al berrinche, porque deja de ser bebé y se integra a un grupo mayor. Por eso ella considera que el área afectiva es la más vulnerable, porque el infante aún no ha dejado el calor de los pañales y todavía requiere el calor del afecto del adulto que pueda en un momento u otro alzarlo, acariciarlo e inclusive hasta cantarle. Pero de pronto, ya no quiere ser ese bebé, precisamente por eso es que se les llama los adolescentes del nivel preescolar, porque no 
son bebés, pero tampoco son grandes. Según esta especialista la etapa entre cuatro y cinco años es un período transitorio bastante fuerte, es como una "pubertad" en medio de la niñez (Comunicación personal, marzo 15, 2000).

$\mathrm{Al}$ respecto la psicóloga Ana Teresa León afirma que a esta edad el niño sigue demandando una enorme cantidad de atención, necesita de contacto y afecto físico (Comunicación personal, mayo 17, 2000). Según Fonseca, estos niños son sumamente sensibles y perciben mucho la aceptación del adulto hacia ellos, razón por lo cual dicha aceptación es muy importante (Comunicación personal, marzo 15, 2000).

Por su parte López expresa que este es un período que toma desprevenido a los adultos, porque todavía no esperan que el niño reaccione como un individuo de cuatro años. Aunque no cuestiona tanto de manera verbal, a nivel de estructura interna del cerebro, de mapas neurales prácticamente todo lo tiene configurado, entonces empieza a cuestionar su mundo por medio de un lenguaje telegráfico (Comunicación personal, abril 19, 2000).

León señala que entre los cuatro y cinco años el niño inicia una etapa de identificación con la figura materna y paterna, cuyo proceso es complejo porque el niño y la niña inician una etapa de despegue de la madre, para identificarse con el padre. A esta edad el papel del padre en el caso de los varones es muy importante (Comunicación personal, mayo 19, 2000).

López considera que este grupo de edad suele ser muy heterogéneo en patrones de desarrollo, por eso se le debe ayudar a estructurar reglas. Los niños entre cuatro y cinco años pueden sufrir de aislamiento por las condiciones de la sociedad, ya que tienen pocas posibilidades de actuar con otros niños de su misma edad, porque generalmente permanecen en su casa, al no asistir a un centro infantil (Comunicación personal, abril 19, 2000).
Este especialista señala que el niño de cuatro a cinco años aún conserva parte del egocentrismo típico de los tres años, su mundo ya no es una extensión de su cuerpo y quiere explorar todas las circunstancias a su alrededor, de ahí su oposicionalidad, porque quiere investigar ese mundo externo y quiérase o no empieza a explorarlo, pero no a nivel motor (tocar, sentir, etc.), sino, una exploración en el orden de lo mental, en el orden de lo neuropsicológico, por eso lo que más contribuye en este proceso es el desarrollo del lenguaje y la comunicación. Dada esta circunstancia al infante le resulta difícil ver las situaciones desde el punto de vista de los demás. No obstante, es de mentalidad vivaz y muy activo, por lo que se vuelve muy versátil.

Teóricamente se plantea que durante este período el niño se muestra más independiente del adulto, se alimenta, se viste, se desviste, y se baña sólo; se cepilla los dientes y no requiere de la ayuda del adulto para usar el baño o escoger su ropa, no obstante, López (Comunicación personal, abril 19, 2000) indica que esta situación no significa que se deba dejar al niño solo, sino que hay que brindarle cierta supervisión. Esta circunstancia de independencia según lo manifiesta el pediatra Ureña (Comunicación personal, abril 17, 2000) también se visualiza porque los padres empiezan a dejar que el niño realice ciertas actividades solo, porque han adquirido confianza en él, o viene o ya ha llegado un hermanito.

Según León (1998) el niño de cuatro a cinco años es capaz de recoger sus juguetes y disfruta de colaborar en algunas tareas domésticas como poner la mesa, lavar los platos, recoger ropa sucia y barrer, entre otras. Además la hora de acostarse y dormir ya no es un problema, pues se encuentra en una etapa de incorporación de rutinas. Algunas veces manifiesta conductas agresivas, aunque su propósito no es totalmente claro. 
La teoría señala que durante este período al niño le gusta practicar el juego solitario y el juego paralelo, sin embargo empieza a hacerse evidente los primeros rasgos del juego de asociación donde hay mayor interacción con sus iguales compartiendo el material de juego. A esta edad los niños también comienzan a manifestar gusto por los juegos competitivos y disfrutan mucho de las dramatizaciones.

$\mathrm{Al}$ respecto Fonseca agrega que a los niños de esta edad les gusta estar con sus iguales, participan con ellos, ya saben que pertenecen a un grupo, lo entienden con bastante claridad, sin embargo son retadores entre ellos mismos. En ocasiones los niños y las niñas tienden a separarse de acuerdo al sexo y organizarse en grupos de tres o cuatro personas (Comunicación personal, marzo 15, 2000).

Según López el juego empieza a tener significado, y se convierte en un elemento central de la vida del niño, porque al usar sus juguetes les da significados, y dependiendo de la manera como los utilice el adulto puede entender algunas de las situaciones que vive el niño en su cotidianeidad (Comunicación personal, abril 19, 2000).

Para López (Comunicación personal, abril 19, 2000) este es el momento fundamental de establecer reglas, dado que los niños andan en busca de límites, por eso es importante ofrecerles un ambiente estructurado, es decir, "darles libertad dentro de una estructura". En este sentido recomienda que los límites deben ser muy claros, desde luego sin establecer reglas que ellos no puedan comprender.

$\mathrm{Al}$ respecto añade que en este periodo se les debe permitir a los niños la posibilidad de investigar y el adulto tiene que tener capacidad para dejar que exploren y establecer los límites en el momento en que se haga una transgresión. Señala que no se deben poner los límites desde antes, ya que esto puede limitar la creatividad del niño, es el adulto quien debe tenerlos claros para actuar en el momento preciso.
Asimismo, manifiesta que a esta edad se le debe dar la oportunidad al niño de resolver en alguna medida sus problemas, pues tiene que aprender a enfrentar y a sentir las consecuencias de lo que hace. No obstante, debe evitarse la agresión infantil, pues por las características de este grupo de edad, los niños podrían estar expuestos a la misma, ya que algunos padres encuentran dificultad para comunicarse eficazmente con sus hijos.

López agrega que durante la etapa de los cuatro a cinco años, el niño demuestra un período de creatividad extraordinaria, se puede sentar con un juguete y armar una historia, ya no depende tanto de sus papás, y se le tiene que brindar el espacio para que él cree su propio mundo. También señala que el niño de esta edad tiene una capacidad de acomodo extraordinaria, por ejemplo si se le muere el papá o la mamá, para el niño podría no tener tanto significado porque aún no ha estructurado una serie de lazos que un niño de seis años ya pudo haber hecho.

\section{Área psicomotriz}

Para Cobos, (1997) el desarrollo psicomotor se encuentra entre lo estrictamente madurativo y lo relacional, o sea que tiene que ver tanto con leyes biológicas como con aspectos interactivos susceptibles de estimulación y de aprendizaje. Para esta autora, la meta del desarrollo psicomotor está dirigida hacia el control del propio cuerpo, involucrando la acción, que le permite al niño entrar en contacto con los objetos y las personas a través del movimiento; y la representación del cuerpo que tiene que ver con el desarrollo de los procesos.

Según se plantea en el programa de estudios del Ciclo de Transición este desarrollo psicomotor involucra tanto la actividad psíquica como la actividad motora e integra complejos procesos de movimiento, acción y organización psicológica. (MEP, 1996). 
Cobos (1997) señala que el desarrollo psicomotor se manifiesta en psicomotricidad gruesa y psicomotricidad fina. La primera se refiere a la coordinación de grupos musculares grandes que involucran actividades como equilibrio, locomoción y salto. La segunda hace referencia a la actuación de grupos musculares pequeños, principalmente aquellos que controlan los movimientos de los dedos.

Esta autora manifiesta que es importante contemplar que el proceso de desarrollo psicomotor se ajusta a la ley céfalo-caudal y a la ley próximo-distal, por eso es que el niño controla inicialmente las partes del cuerpo que están más cerca de la cabeza y del eje corporal.

Desde esta perspectiva el nivel inicial tiene la tarea de favorecer el desarrollo motor en sus tres categorías: locomotor (se refieren a una secuencia de movimientos con un tiempo y un espacio determinado que requieren desplazarse de un lugar a otro); manipulativo (combinación de movimientos con un espacio y tiempo determinados que involucran al individuo con un objeto) y estabilidad (habilidad de mantener el equilibrio en relación con la fuerza de gravedad), se parte del conocimiento del cuerpo, la relación entre éste, el espacio y los objetos; entre sí mismo y los demás. Estas adquisiciones contribuyen al mejoramiento de la estructura corporal y al fortalecimiento de aspectos cognitivos y afectivos (Arce y Rivera, 1988; Gallahue, 1982, MEP, 1996).

Según la Licenciada Marielos Monge, profesional en el área de educación física, antes de los dos años, el niño se encuentra en la etapa de movimientos rudimentarios, y entre los dos y seis años se encuentra en la etapa de patrones básicos de movimiento, donde para cada uno de los patrones pueden encontrarse tres fases: la fase inicial (primeros intentos observables de movimientos en los niños), la fase elemental (período de mayor coordinación y control motor) y la fase madura (movimiento integrado), de acuerdo con esta división los niños con edades entre cuatro y cinco años puede decirse que están en un período de transición entre la fase inicial y la fase elemental (Comunicación personal, mayo 18, 2000).

Desde el punto de vista del pediatra Ureña, el niño alrededor de los cuatro o cinco años ya tiene desarrollado el sistema nervioso, por lo que está en capacidad de caminar adecuadamente, correr, brincar, subir a los árboles, al tobogán, y practicar algunas actividades deportivas. Este especialista considera que a esta edad la actividad motora es una manera de expresión muy importante para el niño, por lo que recomienda no limitarle el ejercicio físico (Comunicación personal, abril 17, 2000).

El doctor Luis López expresa que en términos neuromotores el niño de esta edad ya está completamente desarrollado, únicamente sigue especializando los movimientos porque los procesos de mielinización son muy activos y aún hay aspectos por madurar (Comunicación personal, abril, 19, 2000).

León (1998) manifiesta que durante esta etapa el desarrollo físico refleja menos cambios que en las etapas anteriores. El desarrollo motor es más lento, más variado y más dependiente de los estímulos y las prácticas, contrasta con la intensidad y velocidad del desarrollo mental. Agrega, además, que el cuerpo del niño de esta edad se va asemejando cada vez más al del adulto: el crecimiento de su cabeza disminuye en relación con el resto del cuerpo y las extremidades inferiores crecen con más rapidez.

Esta autora señala que a esta edad las actividades motoras gruesas ocupan gran parte del tiempo del pequeño, pero también ya comienzan a evidenciarse períodos un poco más largos de "tranquilidad". En estos períodos de quietud los niños comienzan a realizar diferentes actividades manuales, muestran por éstas un entusiasmo y dedicación similar al que manifiestan por las actividades de motricidad gruesa. 
Para la Licenciada Ana Isabel Fonseca, especialista en Educación Preescolar, a los cuatro años los niños tienen una marcha bastante poderosa, son ágiles, corren, saltan, se mueven para todo lado. También les agrada caminar sobre barras, y balancearse, buscando saciar la sensación de desequilibrio buscando el equilibrio. Según esta especialista el activismo que caracteriza a estos niños los lleva a cansarse con facilidad, entonces es común que pronto quieran merendar, o saciar su sed, pues no dejan de moverse, es común verlos sentados comiendo y moviendo su cuerpo o algún objeto (Comunicación personal, marzo 15, 2000).

A continuación se describen algunos rasgos importantes en relación con el desarrollo psicomotor de los niños con edades entre cuatro y cinco años, contemplando aspectos tanto de psicomotricidad gruesa como de psicomotricidad fina.

\section{Psicomotricidad gruesa}

La Licenciada Monge señala que entre los cuatro y cinco años se puede esperar que un niño realice patrones básicos de movimiento como caminar y correr en una fase aún no madura. Al respecto recomienda propiciar experiencias donde el niño ejercite estos movimientos desplazándose por el espacio en diversas direcciones, niveles y ritmos, en combinación con otras partes del cuerpo e imitando animales.

Esta especialista indica que a esta edad el infante también es capaz de saltar (salir del suelo con los dos pies juntos para caer sobre los dos pies en el mismo momento) y brincar (salir del suelo con un pie para caer sobre el mismo pie o sobre otro pie, la caída debe ser sobre un único pie), no obstante, señala que un niño de esta edad podría no comprender los vocablos "saltar" y "brincar", por lo que al solicitarle realizar cualquiera de estos movimientos es necesario relacionar la instrucción con algún objeto o animal que lo haga.
En cuanto a las actividades que sugiere para desarrollar estos movimientos, Monge manifiesta que se pueden realizar también en diferentes direcciones, niveles y velocidades; y se pueden complementar con imitación de animales y en el caso del salto puede practicarse desde una altura no mayor a los 25 centímetros (Comunicación personal, mayo 18, 2000).

En relación con los patrones de movimiento de galope, trote, caballito y desplazamiento, esta profesional señala que éstos son combinaciones de los patrones básicos de caminar, correr, brincar y saltar, por lo que el niño con edad entre cuatro y cinco años sólo los puede realizar en un nivel inicial, ya que aún dichos patrones básicos no están maduros.

La Licenciada Monge además explica que entre los cuatro y los cinco años, los movimientos manipulativos como lanzar, apañar y patear, también se encuentran en una etapa de movimiento aún no maduro, por lo que el niño puede intentar realizarlos pero aún debe perfeccionar la ejecución de los mismos. Esta especialista recomienda practicar los patrones de lanzar y apañar en diferentes niveles y distancias, primero con dos manos y luego con una. El patrón de patear se puede desarrollar aprovechando el espacio general.

Por último, en lo que respecta al desarrollo psicomotriz grueso de los niños con edades entre cuatro y cinco años, la Licenciada Monge recomienda enfocar la atención hacia algunos aspectos complementarios del desarrollo de movimientos básicos como los siguientes:

- $\quad$ Prestarle atención a la postura que adopte el niño y a los movimientos que realiza.

- $\quad$ Estimular las destrezas que llevan a una adecuada madurez visual.

- Estimular el área afectiva del niño.

- Utilizar adecuadamente con los niños los conceptos motrices. 
- Ejercitar el patrón de equilibrio en sus modalidades de equilibrio estático (arriba de un balancín) y equilibrio dinámico (caminar sobre una viga).

- Favorecer el concepto de esquema corporal para un mejor desempeño motriz.

\section{Psicomotricidad fina}

Según los resultados obtenidos en las investigaciones realizadas con niños costarricenses por Guevara (1988) y Díaz y Rodríguez (1997), relacionadas con el desarrollo psicomotriz, se puede esperar que un niño entre cuatro y cinco años realice actividades de motricidad fina como las siguientes:

- $\quad$ rasgar y arrugar pliegos o pedazos grandes de diferentes tipos de papel.

- amasar y modelar utilizando diferentes materiales: masa, harina, arcilla, arena, plasticina, entre otros.

- dibujar en espacios grandes sobre papel, pizarras, pavimento, entre otros, con materiales como: dactilopintura, témpera y pincel grueso, tizas y crayolas gruesas, marcadores y lápices de color gruesos, entre otros. En algunos casos pueden dibujar un círculo y hasta imitar trazos verticales y letras.

- engomar sobre superficies amplias con los dedos o con un pincel grueso.

- doblar libremente diferentes tipos y tamaños de papel, y en algunos casos ya pueden doblar de manera dirigida un cuadrado de papel para formar un triángulo.

- utilizar la tijera para recortar libremente diferentes tipos de papel y en algunos casos pueden recortar sobre una línea.

- construir torres con seis bloques, armar rompecabezas de seis a nueve piezas, vaciar líquidos de una botella a un vaso, ensartar cuentas de tamaño mediano.
- abotonar su ropa, cepillarse los dientes, vestirse y desvestirse sin ayuda, doblar y guardar la ropa, peinarse sin ayuda, poner la mesa y regar las plantas.

- $\quad$ según Lowenfeld (1980), el niño de esta edad es capaz de representar la figura humana por medio de un monigote.

\section{Área cognitiva}

Esta área del desarrollo humano involucra el proceso mediante el cual el niño va adquiriendo conocimientos acerca de sí mismo, de los demás y del mundo en que vive, incluye también el estilo que tiene para aprender y para pensar e interpretar las cosas. En este proceso el lenguaje juega un papel muy importante porque contempla todas las conductas que le permiten al niño comunicarse con las personas que le rodean.

Mira (1989) plantea que el niño preescolar pasa por tres estadios en el desarrollo de las estructuras del pensamiento. Primero se ubica el estadio del pensamiento preconceptual, en el que el niño adquiere la función simbólica mediante la cual sustituye la realidad por un mundo ficticio. Luego el niño pasa por el estadio del pensamiento intuitivo, donde por medio de la intuición considerada como la lógica de la primera infancia, el niño logra la interiorización de las percepciones en forma de imágenes representativas y de las acciones en forma de experiencias mentales. Por último se encuentra el estadio de operaciones concretas, que corresponde aproximadamente a la entrada del niño a la escuela primaria, donde se coordinan los esquemas intuitivos y aparecen agrupados en una totalidad.

Interpretando a esta autora, puede decirse que el niño con edad entre cuatro y cinco años está en un período de transición entre el estadio de pensamiento preconceptual y el estadio de pensamiento intuitivo, para el cual ella define las siguientes características: 
- La formación de conceptos se da a partir de experiencias con material concreto: el niño construye los conceptos primarios partiendo de la relación que establece con experiencias concretas basándose en la acción y apoyándose en la percepción. Los primeros conceptos cuantitativos los elabora mediante parejas de contraste: más-menos, muchos-pocos, grandepequeño, alto-bajo, entre otros.

- Pensamiento irreversible: a pesar de que la intuición es una acción interiorizada, no es reversible, ya que en el plano de la representación es más difícil invertir las acciones, además la reversibilidad supone la noción de conservación.

- Falta de conservación: el niño, en este período, aún no puede comprender que la cantidad, continua o discreta, se conserva a pesar de las modificaciones en las configuraciones espaciales.

- Primacía de la percepción: el esquema intuitivo permite hacer comparaciones entre cantidades, y establecer criterios de equivalencia o diferencia. Sin embargo, estas comparaciones son perceptivas, es decir, dependen de la correspondencia óptica, pues en el momento en que se altera la configuración espacial, desaparece la equivalencia, por lo que aplica una comparación perceptiva del espacio ocupado. El niño dice, por ejemplo, al variarle la presentación de una bola de plasticina por una figura alargada: "hay más porque es más largo".

- Paso de una centración simple a dos centraciones sucesivas: por ejemplo, corrige o sustituye la centración sobre la altura: "hay más porque es más alto" por una descentración sobre la amplitud: "hay menos porque es más delgado", pero todavía considera ambas relaciones alternativamente y no al mismo tiempo.

Esta caracterización referida por Mira
(1989), corresponde a lo que Piaget denomina nivel de conocimiento preoperacional, el cual se caracteriza porque los niños aún no pueden invertir las operaciones cognoscitivas y les resulta difícil asimilar más de un aspecto de una misma situación de manera simultánea, y manifiestan todavía un poco de dificultad para manejar la representación simbólica de los objetos; razón por la cual mantienen relación con conceptos de objetos reales o concretos como animales u objetos visibles y palpables (Reys et al. 1984).

De acuerdo con los niveles de desarrollo del aprendizaje caracterizados por Bruner (s.f.), citado por Reys, esta etapa corresponde al nivel de las representaciones, que se caracteriza por la manipulación, construcción y organización de los objetos del mundo real, por medio de la interacción directa.

$\mathrm{Al}$ respecto la Máster Ana Teresa León (Comunicación personal, mayo 17, 2000) señala que existe muy poca información costarricense en relación con los conceptos que adquieren los niños de edades entre cuatro y cinco años, sin embargo, agrega que tomando como base la Asociación Nacional de Educación de Niños Pequeños de Estados Unidos, se sugiere que a esta edad no se utilice material gráfico, porque el proceso cognitivo que el niño está desarrollando debe girar en torno a objetos reales. De esta manera, para que se dé un proceso educativo pertinente es importante tener claro qué conceptos dominan los niños y a partir de esta situación ofrecerle oportunidades para la construcción de nuevos conceptos por medio de experiencias vivenciales.

Dienes, citado por Reys (1984), señala que esta edad constituye un período de transición entre el nivel de juego libre, en el que el niño interactúa directamente con materiales concretos y el ambiente, y el nivel de generalización, donde patrones, aspectos regulares y comunes son observados y abstraídos por medio de diferentes modelos.

Partiendo de estas características, la teoría menciona que los niños entre cuatro 
y cinco años pueden establecer relaciones entre objetos, agrupándolos por color, forma, textura o tamaño. También, según lo señala la especialista en Educación Preescolar, Licenciada Ana Fonseca, se interesan por la adquisición de la numeración, aunque teóricamente se sostiene que el concepto de número todavía se encuentra en proceso de construcción. La Licenciada Fonseca manifiesta que estos niños son coleccionadores a medias, porque aún no tienen la capacidad de sistematizar lo que traen al aula, su interés es momentáneo, en el sentido que se sacian con rapidez, o sus intereses pueden sustituirse fácilmente (Comunicación personal, marzo 15, 2000).

Esta profesional también indica que a esta edad los niños son sumamente imaginativos, tienen gran facilidad para crear, para convertirse en cualquier cosa, todavía su fantasía es muy fuerte. Ella considera que a esta edad es muy importante el drama, el juego simbólico y la experimentación. Al respecto Rojas (1998) señala que entre los cuatro y cinco años el niño emplea el juego como medio para el aprendizaje.

Por otro lado, Fonseca (Comunicación personal, marzo 15, 2000) apunta que según lo observado en su experiencia como supervisora de práctica docente, los niños entre cuatro y cinco años demuestran períodos de atención que pueden oscilar entre 15 y 20 minutos en una misma actividad.

En cuanto al desarrollo lingüístico se sostiene que los niños de esta edad ya han adquirido las principales reglas gramaticales de su lengua materna. El neurodesarrollista Luis López, manifiesta que el lenguaje está prácticamente estructurado desde el punto de vista sintáctico y morfológico, aunque la combinación que el niño hace es relativamente escasa, porque utiliza oraciones de tres o cuatro palabras (Comunicación personal, abril 19, 2000).

Este especialista expresa que a esta edad se espera que el niño tenga una estructura en términos fonológicos y sintácticos muy similar a la de un adulto, pues a partir de ahí lo que empieza es a rellenar, a cargar mapas cerebrales de lenguaje con un aumento de significados y vocabulario, pero en términos de organización de lenguaje, ya está desarrollado. También señala que entre los cuatro y cinco años el niño puede contar una historia dándole un carácter absolutamente real, por lo que se convierte en un cuentacuentos extraordinario. Puede sentarse frente al cepillo o la muñeca y contar una historia que sorprende al adulto, ya hay una prosodia, ya no llama al papá, a la mamá o a los amigos de igual manera, sino que le impregna emoción a lo que dice.

Según López, el cerebro y el lenguaje son las estructuras que más se desarrollan a esta edad. Si se quiere que un niño tenga una buena estructura de lengua materna, este es el momento para estimularla y reforzarla, él no recomienda la enseñanza de un segundo idioma hasta que este proceso no haya concluido. En este sentido considera que si un niño llega a los cinco años y todavía no ha desarrollado un lenguaje que sea funcional en términos de comunicación, el pronóstico es considerablemente oscuro para él. Sostiene que a pesar de que teóricamente se podrían diagnosticar trastornos de lenguaje y comunicación antes de los cuatro años, es justamente en este grupo de edad en el que con más frecuencia se diagnostica un problema de este tipo, porque generalmente es el momento donde los adultos reaccionan con preocupación (Comunicación personal, abril, 19, 2000).

Por otro lado, la Master Marielos Murillo (2000), especialista en Lingüística, manifiesta que actualmente resulta difícil caracterizar el lenguaje por edades, dado que algunos niños de cuatro años ya tienen un dominio de la lengua que antes se esperaba para un niño de seis años, esto, porque tiene mucha estimulación, además la evolución de la especie humana también influye. En este sentido ella recomienda hacer un diagnóstico para identificar por dónde va el niño y así definir qué trabajar con él. 
No obstante, esta especialista expresa que en términos generales los niños de esta edad manejan una estructura básica de su lengua y un vocabulario básico, el cual es bastante concreto, ya que pueden utilizar expresiones como ésta es la caja de un cassette, pero no así términos como democracia o solidaridad que representan cuestiones intangibles. Respecto del vocabulario que utilizan, la especialista lo cataloga de carácter contextual, es decir del medio que los rodea: su aula, su casa, su comunidad, y enfatizan que el desarrollo del lenguaje depende en gran medida de la estimulación que se le brinde al niño (Comunicación personal, abril 6, 2000).

En cuanto a la sintaxis que manejan los niños de esta edad, Murillo (2000) señala que utilizan oraciones simples, siendo muy descriptivos, ya que aún no poseen la capacidad cognitiva para planificar un discurso narrativo, mucho menos para anticipar lo que el otro interlocutor va a decir, especialmente porque todavía conservan características de una personalidad egocéntrica, lo que en ocasiones permite observar a un niño hablar de sus cosas independientemente de lo que expresa el otro interlocutor, esto porque no puede asumir la posición de la otra persona, a pesar de que se inicia en el juego cooperativo.

Según Cassany (1997), lo anterior le impide conducir un discurso y dar por terminada una conversación, ya que el niño de esta edad habla de lo que siente, de lo que vive en ese momento o de lo que imagina, y lo habla el tiempo que desea, el tiempo que siente gozo y placer por lo que realiza, pues tal y como lo reafirma Fonseca (2000), estos niños son conversadores, pero terminan su conversación cuando se terminó el interés de lo que querían comunicar.

Sin embargo, Cassany (1997) señala que el niño entre los cuatro y cinco años está en capacidad de iniciar o proponer un tema, ésto se observa en sus juegos, y en los salones de clase cuando el niño demanda conversar de un tópico específico que le llama la atención. Además puede negociar el significado de su discurso, al seleccionar el nivel de explicación y evaluación del mismo.

Con respeto de la habilidad lingüística de recepción, el autor señala que los niños de cuatro a cinco años por las habilidades logradas hasta el momento, por su capacidad cognitiva y su desarrollo, no están listos por el momento para poner en práctica las microhabilidades de reconocer y de segmentar lo que se le dice en sonidos, palabras, verbos, etc. A esta edad el niño no tiene un dominio sintáctico que le permita reconocer los fonemas, morfemas y palabras en forma aislada dentro de su lengua.

Esta misma situación lo limita para distinguir las ideas relevantes de un discurso, discriminar lo importante de una frase o relato dicho, o entender los supuestos o las frases con doble sentido. También le es difícil comprender la estructura del discurso, anticiparse al actuar de su interlocutor y tratar de hacer inferencias con respecto de la persona o personas que están con él y de lo que se dice en ese momento.

Por el contrario, a los cuatro años el niño es capaz de comprender un mensaje claramente si éste parte del conocimiento del lenguaje que posee, puede entender lo que se le dice si no existe un gran listado de peticiones que lo confundan.

En cuanto a los interlocutores con los cuales se comunican estos niños, el pediatra Jorge Ureña, manifiesta que suelen comunicarse bastante bien con sus iguales, pero a veces rehúsan comunicarse con la gente adulta, por ejemplo se niegan a saludar o a despedirse (Comunicación verbal, abril 17, 2000).

En relación con la adquisición de fonemas, la especialista Murillo (2000) manifiesta que desde los tres años el niño ya domina las vocales y los sonidos nasales de la $/ \mathrm{m} /$, la $/ \tilde{n} /$, la $/ 1 /$. Y a partir de los cuatro años la /r/ cuando pertenece a una comunidad de vibrante múltiple como Guanacaste.

También señala que en el Valle Central los niños de esta edad no manejan ni la /r/ ni la/f/, pues les son más difíciles de pronunciar, 
por eso en algunos casos los sustituyen por otros fonemas, por ejemplo callo por carro.

Considera, de acuerdo con sus investigaciones, que los fonemas que les resultan más fáciles a todos los niños cuya edad oscila entre cuatro y cinco años son los siguientes: /b/, /p/, /m/, /t/, /d/, /k/, /g/, /j/, /ch/, /y/.

Respecto de la utilización del lenguaje, algunos especialistas sostienen que el niño de esta edad es conversador y ruidoso, combina las palabras con la acción al hablar, y disfruta de juegos verbales. Al respecto, Fonseca (2000) manifiesta que los niños de edades entre cuatro y cinco años son grandes manejadores del lenguaje porque lo han descubierto, lo han ido sistematizando en una comunicación más aceptada socialmente, entonces integran con gran gusto y placer nuevas palabras, juegan con los sonidos. Tal vez esto se puede relacionar con características de las edades anteriores cercanas, pero ya no es la exploración motora propia del bebé, ahora lo que hace es integrar palabras o hasta inventarlas. Esto lo acompaña con la explosión motora, entonces, no solamente hablan sino que lo gesticula, hay una integración muy pura entre el lenguaje verbal y gestual.

Esta especialista también señala que estos niños muestran una expresión gráfica muy comparativa con la adquisición del lenguaje oral, buscan una simbolización, comienzan a establecer relaciones con la realidad y sus dibujos tienen una identidad definida. Además, les gusta imitar la letra convencional, les gusta escribir, porque tienen un gran interés de entrar al mundo adulto.

Para esta educadora el fortalecimiento del desarrollo integral del niño con edad entre cuatro y cinco años puede abordarse a partir del movimiento y del lenguaje, pues constituyen el medio expresivo más rico que tiene para explorar el mundo y para comunicarse.

\section{Conclusión}

Como puede apreciarse el niño con edad entre cuatro y cinco años está en un periodo de transición en lo que respecta a su desarrollo; ha dejado de ser un "bebé" pero todavía no es un niño "grande", es por esta razón que requiere una atención y un trato particular, procurando sobretodo fortalecer su autoestima, la seguridad en sí mismo y la posibilidad de establecer relaciones tanto con sus iguales como con los adultos que le rodean.

Bajo estas circunstancias toda experiencia educativa que se brinde a niños con estas edades debe partir del conocimiento de sus características, para poder identificar sus necesidades e intereses reales y propiciar un proceso educativo pertinente.

\section{Referencias bibliográficas}

Arce, R. Y Rivera, J. Estandarización de una batería de escalas de clasificación de patrones básicos locomotores y manipulativos para niños costarricenses en edad preescolar. Seminario de Graduación para optar por el título de Licenciatura en Educación Preescolar. San José, Costa Rica: Universidad de Costa Rica. 1988.

Cassany, D., Luna, M., \& Sanz, G. Enseñar lengua. Segunda edición. Traducción de Susana Esquerdo. España: Graó. 1997.

Cobos, P. El desarrollo psicomotor y sus alteraciones. Manual práctico para evaluarlo y favorecerlo. Madrid, España: Ediciones Pirámide. 1997.

Díaz, S. \& Rodríguez, J. Características del desarrollo psicomotor en niños de dos a cinco años, del CEN de las comunidades de Cot de Cartago y Vuelta de Jorco, Aserrí. Proyecto de Graduación para optar al grado de Licenciatura en Educación Preescolar. San José, Costa Rica: Universidad de Costa Rica. 1997.

Fonseca, A. Características generales del comportamiento del niño con edades 
comprendidas entre 4 y 5 años. Comunicación personal. San José, C.R. 2000.

Gallahue, D. Understanding motor development and movement experiencies for young childen. U.S.A.: John Wiley and Sons. Inc. 1982.

Guevara, M., Herrera, A., Rodríguez, G. \& Solano, M. Problemática de los niños preescolares atendidos en el Programa CEN (Centros de Educación y Nutrición) y CINAI (Centros Infantiles de Nutrición y Atención Integral) desde la perspectiva del personal de salud. Tesis de graduación para optar por el grado de Licenciatura en Ciencias en la Educación con énfasis en Educación Preescolar. Heredia, C. R.: Universidad Nacional Autónoma. Centro de Investigación y Docencia en Educación (CIDE). 1988.

León, A. Desarrollo y atención del niño de 0 a 6 años. Primera parte. Tercera reimpresión de la segunda edición. San José, Costa Rica: EUNED. 1998.

León, A. Características del desarrollo del niño con edades comprendidas entre 4 y 5 años. Comunicación personal. San José, C.R. 2000.

López, L. Desarrollo neurológico del niño con edades comprendidas entre 4 y 5 años. Comunicación personal. San José, C.R. 2000.

Lowenfeld, V. Desarrollo de la capacidad creadora. Segunda edición. Buenos
Aires, Argentina: Editorial Kapelusz. 1980.

Ministerio de Educación Pública. Programa de estudios, educación Preescolar: Ciclo de Transición. San José, Costa Rica: El Ministerio. 1996.

Mira, R. Matemática viva en el parvulario. Barcelona, España. Ediciones CEAC. 1989.

Monge, M. Características del desarrollo psicomotor del niño con edades comprendidas entre cuatro y cinco años. Comunicación personal. San José. 2000 .

Murillo, M. Desarrollo del lenguaje del niño con edades comprendidas entre 4 y 5 años. Comunicación personal. San José, C.R. 2000.

Mussen, P.; Conger, J. \& Kagan, J. Desarrollo de la personalidad en el niño. Segunda edición. México: Editorial Trillas. 1978.

Reys, R. et al. Helping Children Learn Mathematics. New Jersey. Prentice Hall. 1984.

Rojas, M. Educación científica y matemática para el niño preescolar l. San José, Costa Rica. EUNED. 1998.

Ureña, J. Desarrollo físico del niño con edades comprendidas entre 4 y 5 años. Comunicación personal. San José, C.R. 2000.

Jeanneth Cerdas Núñez Docente, del Ministerio de Educación Pública

Ana Polanco Hernández Profesora de la Escuela de Formación Docente de la Universidad de Costa Rica 